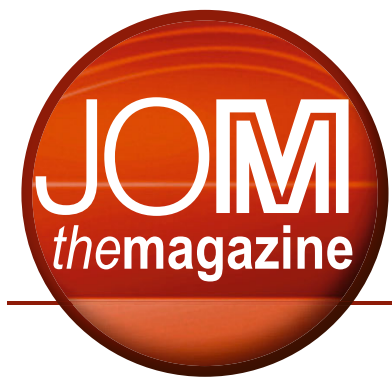

\title{
meet a member
}

\section{Dancing Lifts Up Lauren Garrison}

\section{Lynne Robinson}

Dance and engineering may seem worlds apart. But, in Lauren Garrison's mind, the two disciplines could not be more intertwined.

"I've always loved learning and have a good memory," said Garrison, Weinberg Fellow, Oak Ridge National Laboratory. "I think my ability to understand and memorize technical information also allows me to catch on to new dance moves quickly and memorize routines very easily."

The connection between her two passions is even more evident when Garrison expresses her creativity through choreography. "I feel that my training in engineering and mathematics shows up in some of my routines and the formations I use," she explained. "Just as I would visualize an engineered system of many parts interacting, I visualize the dancers moving through the formations and

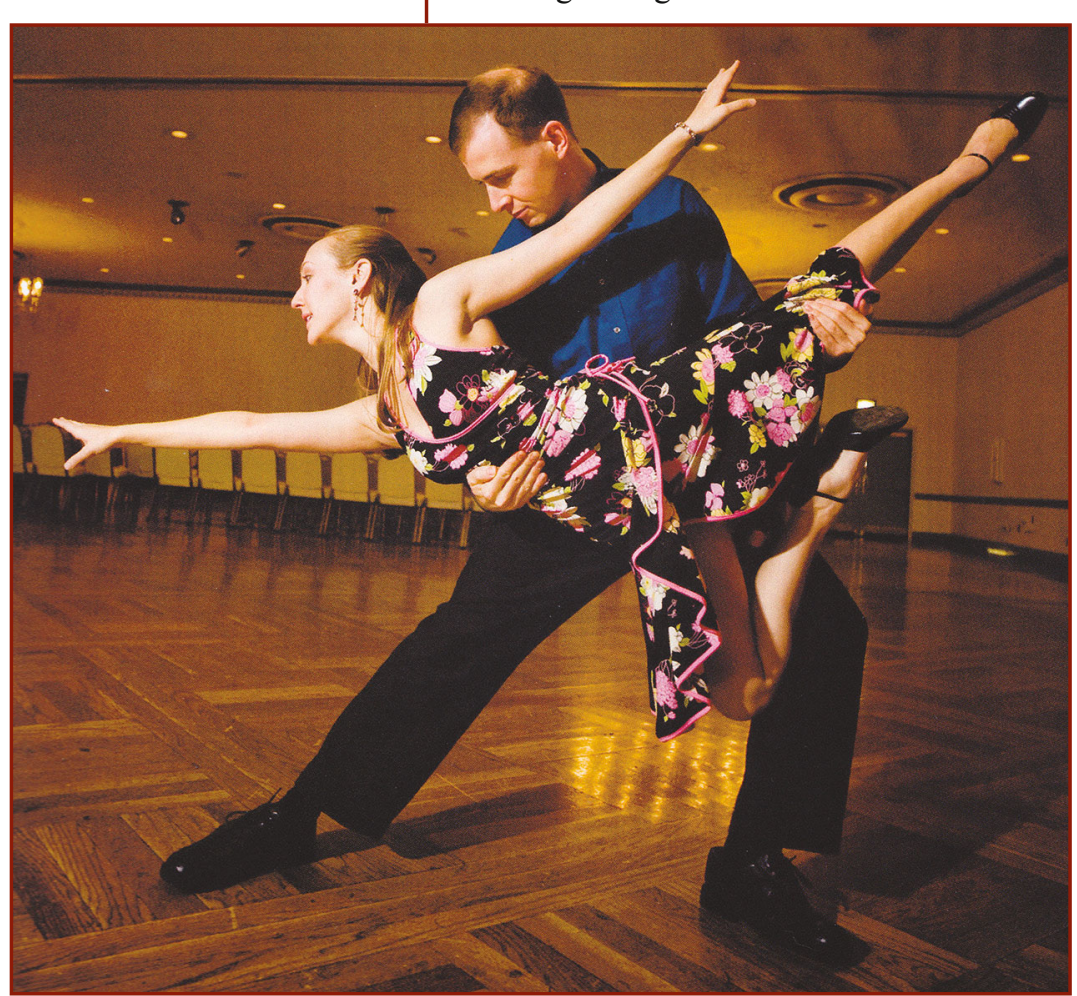

interacting with each other."

Garrison has been dancing since second grade and performed with both her high school dance team and the University of Illinois, Urbana-Champaign, 3Spot Dance Troupe as an undergraduate. She was also selected as a Universal Dance Association (UDA) instructor for two summers, teaching various technique classes and seminars, as well as routines which the students were required to perform before judges at the conclusion of week-long camps. That experience, she observed, offered her insights that were applicable far beyond the dance studio.

"I realized that the primary factor for whether or not a dancer did well at the final performance had little to do with skill and mostly to do with how well I taught and drilled the routine," she said. "I think this is true in all teaching environments, both dance and scientific. The teacher has the main responsibility for making the material understandable and showing the students how it is used and applied. If the teacher does not do that effectively, it doesn't matter how skilled the dancer or smart the student, the final performance will be poor."

Garrison has studied many different types of dance over the years- jazz, tap, ballet, modern, lyrical, partner dancing, and hip hop, to name a few. "Each style has aspects that I like," she said. "I enjoy hip hop a lot because it is very current and the movements often challenge you to use the body in difficult and creative ways. By contrast, there are certainly very difficult moves in ballet and the technique takes much time to master, but all the movements are contained within the parameter space of a very strict set of rules."

Partner dancing, though, holds a special place in Garrison's heart. "Having a partner to do lifts with essentially opens up a third dimension for dancing," she 
explained. "There are just so many types of moves that can only be done with two people."

"And, partner dancing is also how I met my husband," she continued. "We were swing partners with the 3Spot Dance Troupe," she said, noting that one of her favorite memories was choreographing and performing a piece with her husband when they danced on the college team.

Garrison still finds time in her busy life to take classes at the Oak Ridge Academy of Dance, commenting "I think that pursuing activities and interests outside of work is very important. The mind needs a break, and I feel that I can work more effectively when I take the time to do things I really enjoy outside of work." This past spring, she managed to squeeze in four classes a week and performed in the academy's end-of-theyear show. "At the studio, I practice the techniques and learn new moves, but it can't compare to the thrill of performing," Garrison said. "On the stage is when I get to pour emotion into a piece and share that with the audience."

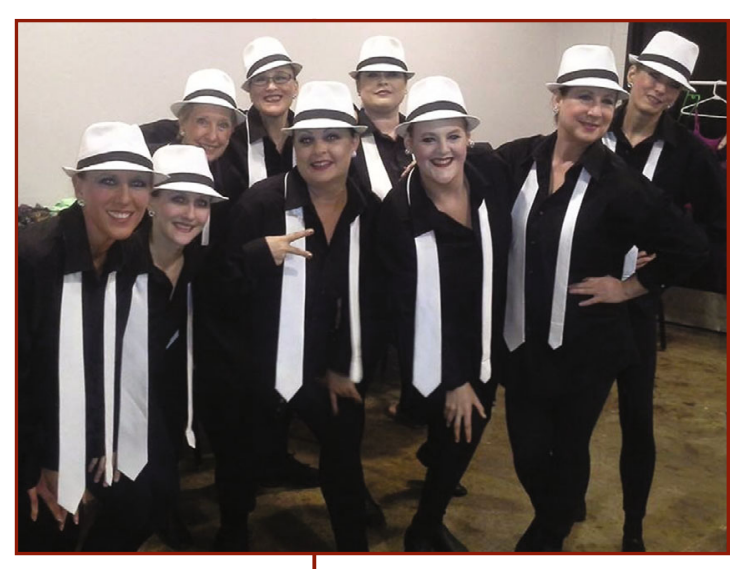

Garrison (second from left) before a performance at the Oak Ridge Academy of Dance.

\section{member news}

\section{TMS Members Selected for Highly Cited Researchers List}

Thomson Reuters, the organization that generates the ISI Web of Knowledge citation index, released its 2014 list of Highly Cited Researchers in July as a follow up to a similar list that it posted in 2001. This new list was based on papers indexed between 2002 and 2012, tracking authors who published numerous articles ranging among the top one percent of the most cited in their respective fields of study in the year of publication.

TMS congratulates the following members who are among this year's 147 Highly Cited Researchers in the field of materials science:

- Mingwei Chen, Professor, Institute for Materials Research, Tohoku University

- Terence G. Langdon, Professor,

University of Southern California

- Ju Li, Associate Professor, Massachusetts Institute of Technology

- Ke Lu, Director, Institute of Metal Research, Shenyang

- Lei Lu, Institute of Metal Research, Shenyang

- Evan Ma, Professor, Johns Hopkins University

- Ramamoorthy Ramesh, Deputy Director for Science and Technology, Oak Ridge National Laboratory

- Subra Suresh, President, Carnegie Mellon University

- Thomas Webster, Professor and Chair, Bioengineering and Chemical Engineering, Northeastern University

- Yuntian Zhu, Distinguished Professor, North Carolina State University

\section{Lance Snead Named Corporate Fellow}

Lance L. Snead, Associate Division Director, Materials Science and Technology Division, Oak Ridge National Laboratory (ORNL), has been recognized as an ORNL Corporate Fellow. Among the lab's highest honors, the corporate fellow designation recognizes significant accomplishments and continuing leadership in scientific, engineering, and technological fields. Snead was specifically cited for "being the leading international expert on radiation effects in silicon carbide and other ceramic composites for fusion and advanced fission reactors." Among his many accomplishments, Snead has served as guest editor for a number of journals within his field, publishing more than 210 papers with 4,450 citations. He received his doctorate in nuclear engineering from Rensselaer Polytechnic Institute.

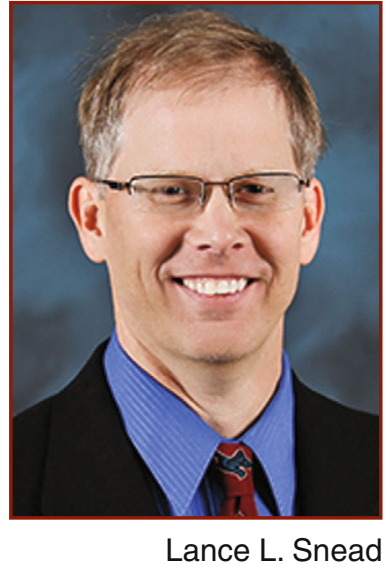

